\title{
Comparative Analysis of Soaking Time on Hardness and Tensile Strength for Mercerization Treated Raffia Palm Fibre
}

\author{
Nnorom Obinichi \\ Mechanical Engineering, University of Port Harcourt, Choba, Port Harcourt, Nigeria \\ Tobinson A. Briggs* \\ Mechanical Engineering, University of Port Harcourt, Choba, Port Harcourt, Nigeria
}

\begin{abstract}
The paper aims to study the soaking time on hardness and tensile strength for mercerization modified raffia palm fibre, which will be gathered, extracted, retted, processed and treated with $5 \%$ and $10 \% \mathrm{NaOH}$ concentration using a soaking time of $60(1 \mathrm{hr}), 120(2 \mathrm{hrs}), 180(3 \mathrm{hrs})$ and 240 minutes( $4 \mathrm{hrs})$ at a varying fibre length of $50,60,70$ and $80 \mathrm{~mm}$. From the experiment conducted for hardness, the maximum optimum value of $395 \mathrm{HB}$ was recorded at $60 \mathrm{~mm}$ fibre length for 2 hours using $10 \% \mathrm{NaOH}$ concentration. While the strength gave an average optimum value of $768 \mathrm{Mpa}$ at $70 \mathrm{~mm}$ fibre length for 3 hours using $5 \% \mathrm{NaOH}$ concentration at varying the soaking time for mercerization modified fibre. The fibre was grounded into smaller particles size and reinforced with high-density polyethylene (HDPE). Different test samples for the production of oil and gas facilities like pipes and pipe joints, a storage system (pressure vessel), etc. and also for producing interior paneling for aircraft and automobiles, household tables and chairs, window frames, laptop cases, and another consumer item.
\end{abstract}

Keywords: Raffia Palm, Soaking Time, Mercerization, high-density polyethylene

DOI: $10.7176 /$ ISDE/10-6-02

Publication date:July $31^{\text {st }} 2019$

\subsection{Introduction}

It has been a growing environmental consciousness during the last few years, which increased the interest to use natural fibers such as raffia palm, kenaf, jute, hemp, flax, and coir instead of human-made (synthetic) fibers, i.e., glass fibers, aramid fibers, and carbon fibers in composite materials. Natural fibers have advantages which are low-density with high specific properties (properties per unit weight), inexpensive, abundance, and less tool wear. Also, natural fibers are renewable, recyclable, biodegradable and locally available (Oksman, 2000). Tensile strength and tensile modulus of natural fibers are remarkably lower than those of synthetic (human-made) fibers; all natural fibers offer significant cost advantages. The differences in fiber structure and overall environmental conditions during growth affect the natural fibers mechanical properties. The modification of natural fibre is carried out in different ways to yield reinforcing fillers having different mechanical properties. They could have mechanical properties comparable to those of glass fiber-polymer composites in some treatment (Bledzki and Gassan, 1999). Furthermore, the natural fiber-polymer composites with lightweight have a potential weight saving advantage. Meanwhile, the synthetic (human-made) fibers have serious drawback due to high cost, non-renewable, non-recycle, nonbiodegradable, and riskful. Proponents of natural fiber composites have highly exploited the shortcoming. Recently intensive researches have been carried out in several countries to study the use of natural fiber for composite applications. The automotive industries have already used natural fibre to produce by natural composites. According to Al-Qureshi et al. (2001), jute fiber reinforced composite and hybrid composite were developed, manufactured and assembled a small prototype car with all body panels. Furthermore, a significant step towards higher performance applications of automobiles was achieved with the door panels of the E-Class Mercedes-Benz. To develop the world, this sector is of interest. The door panels which were manufactured using flax/sisal mat embedded in an epoxy resin matrix has shown a remarkable weight reduction of about $20 \%$. Furthermore, their mechanical properties that are important for passenger protection in the event of an accident have been improved. Moreover, the flax/sisal material can be molded in complicated shapes (Schuh, 2004). A production stage has reached for several building components manufactured from agricultural materials. They include low-density insulation boards, hard boards, particle boards, medium-density fiber boards and other building system components such as walls and roofs. It has been reported that in Africa, the strong particle board was made from combinations of bagasse (sugar cane residue), wood shavings, mangrove bark and corncobs (Taylor, 2004). Usually, natural fibers are made up of cellulose, hemicellulose, and lignin. It is useful to have the information on fiber characteristics and the factors to expand the use of agro-fibers for composites, which affect the performance of the fiber (Rowell et al., 2000). This study intends to analyze the hardness and tensile strength on soaking time for mercerization treated raffia palm fibre and the results obtained are presented. 


\section{Methodology}

\subsection{Materials}

The raffia palm fibres were obtained from a river located at Ikwerre local government area, Port Harcourt, River State. In this study, the following materials were used; they comprise of distilled water, weighing scale, oven, thermometer, $\mathrm{pH}$ meter and graduated cylinder, glass beaker, plastic cup.

\subsection{Methods}

\subsubsection{Water Retting and Fibre Extraction}

The fibre was extracted and retted by retting method which is a rotting process of raffia palm in water. Developing and processing of the fibre very quickly the remnants of the raffia palm were soaked in water using about $2 \%$ detergent for three days until the fibres are distinct from pectin, hemicelluloses, oily substances, and other impurities. After that, the fibres were thoroughly washed and allowed to dry in the sun for two days. Figure 2.1 shows the extraction of raffia palm fibers before washing.

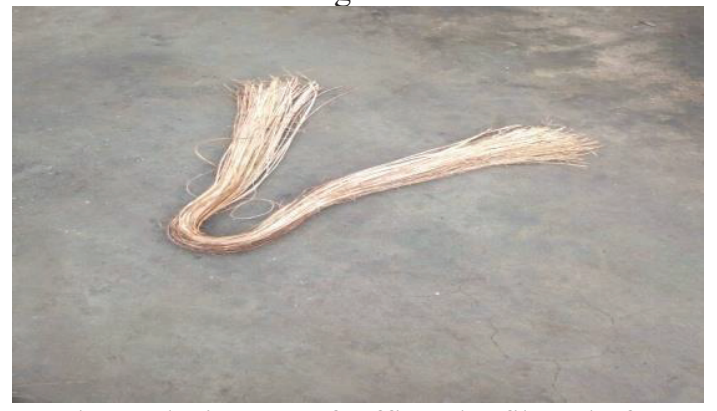

Figure 2.1 shows the images of raffia palm fibers before washing

Chemical treatment of the RPFs

The fiber was modified using (Aziz and Ansel, 2004) mercerization treatment techniques

(a) Mercerization (Alkalization) Treatment

After cleaning the fibres, it was were soaked using $5 \%$ and $10 \%$ sodium hydroxide $(\mathrm{NaOH})$ solution at a temperature of $30^{\circ} \mathrm{C}$ for an hour. Later the fibres were removed from the $\mathrm{NaOH}$ solution and washed thoroughly using plentiful of distilled water to remove all the excess $\mathrm{NaOH}$ (or nonreacted alkali).

2.2.2 Raffia palm fibre characterization

Hardness and Tensile test were investigated to analyze the hardness and strength for mercerization (alkalization) modified fibre using $5 \%$ and $10 \%$ concentration of $\mathrm{NaOH}$ to determine the soaking time for $60(1 \mathrm{hr}), 120(2 \mathrm{hr})$, $180(3 \mathrm{hr})$ and 240 minutes $(4 \mathrm{hr})$ at varying fibre length of $50 \mathrm{~mm}, 60 \mathrm{~mm}, 70 \mathrm{~mm}$ and $80 \mathrm{~mm}$.

- Hardness Test

The hardness of a material is defined as its resistance to permanent deformation, indentation or scratching. The hardness values of the developed fibre samples were measured using Rockwell Hardness Tester on MScale by ASTM D785. The results of the hardness test were recorded too.

- Tensile Test

The fibres undergo a simple tensile test. The testing was carried out using Dynamic Mechanical Analyzer (DMA Q800) with TA instrument that has a thin film tensile fixture. The sample was measured by subjecting it to force ranging from 0 to 17 Newton.

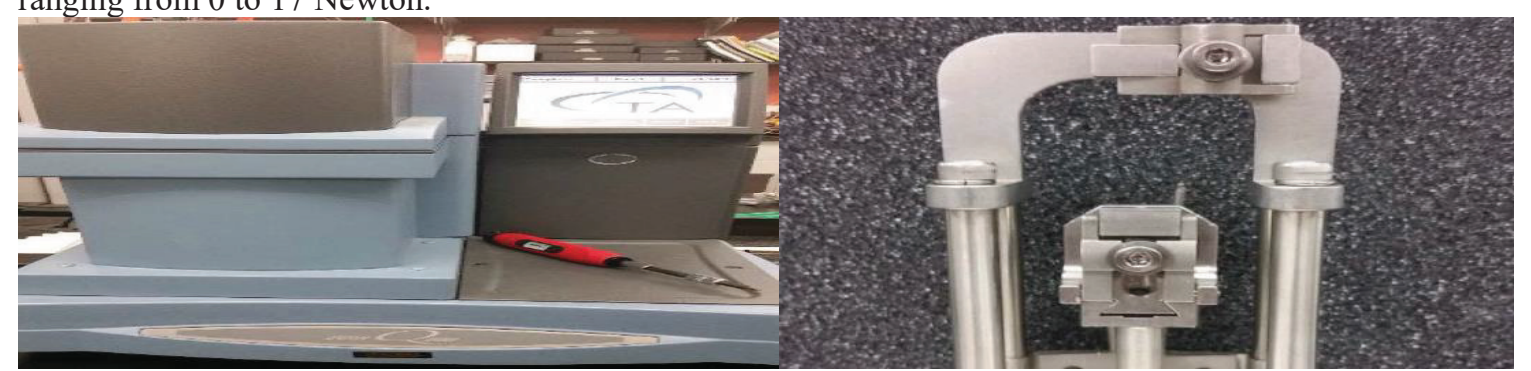

Figure 2.2: Shows the diagram of the dynamic mechanical analyzer (DMA) (left) with thin film test fixture (right). (Source: Patrick, 2016)

Since the sample that was tested is not thin films, more samples are needed for testing. A thick cardstock paper ( 1 in. by 0.5 in.) was used by cutting out small rectangular tabs, and a hole punch removed the material from the tab. $7.8 \mathrm{~mm}$ diameter hole or 0.3 inches was produced, and it was taken as the gauge length of the fibre sample. Superglue was used to either side of the tab with single raffia palm and dried overnight. The DMA instrument was used to clamp the thin film test fixture with the tabbed fibre specimens; the raffia palm fibre was not cut while cutting the tab at the thin sides. The thin sides were cut to guarantee that the raffia palm fiber was the only thing 
receiving the force from the DMA. Metcalf-Doetsch, (2013) design is similar to the tabbed sample. The prepared samples underwent a simple tensile test within the DMA. And the test was conducted using a constant rate of extension of $0.5 \mathrm{~mm}$ per minute. At higher rates of extension, the DMA could not uphold continuous rate; the linear stress-strain curve shows that the sample failed easily. About ten replicate of the alkali treated fibre samples were tested. The outcome of hardness and strength test at a varying length of fibre; $50,60,70,80 \mathrm{~mm}$ using soaking time of 60 (1hr), 120(2hrs), 180(3hrs) and 240 minutes(4hrs) for mercerization modified fibre was documented.

\section{Results and Discussion}

Table 1 to 4 and figure 1 to 4 illustrates the hardness and tensile strength for mercerization treated raffia palm using $5 \%$ and $10 \%$ concentration of $\mathrm{NaOH}$ at different soaking time of 60 (1hr), 120(2hrs), 180(3hrs) and 240 minutes (4hrs) with a varying length of the fibre; 50, 60, 70 and $80 \mathrm{~mm}$ were examined and the result documented. Table 1: Hardness test for mercerization treated raffia palm fibre using $5 \% \mathrm{NaOH}$ concentration

\begin{tabular}{|c|c|c|c|c|}
\hline Fibre Replication & $\begin{array}{c}\text { Hardness HB } \\
\text { @50mm } \\
\text { 60mins }(1 \mathrm{hr})\end{array}$ & $\begin{array}{c}\text { Hardness HB } \\
\text { @60mm } \\
120 \mathrm{mins}(2 \mathrm{hrs})\end{array}$ & $\begin{array}{c}\text { Hardness HB } \\
\text { @70mm } \\
180 \mathrm{mins}(3 \mathrm{hrs})\end{array}$ & $\begin{array}{c}\text { Hardness HB } \\
\text { @8 80mm }\end{array}$ \\
\hline R1 & 176 & $276 \mathrm{mins}(4 \mathrm{hrs})$ \\
\hline R2 & 231 & 141 & 143 & 148 \\
\hline R3 & 222 & 93 & 285 & 170 \\
\hline R4 & 210 & 167 & 110 & 198 \\
\hline R5 & 150 & 125 & 176 & 172 \\
\hline
\end{tabular}

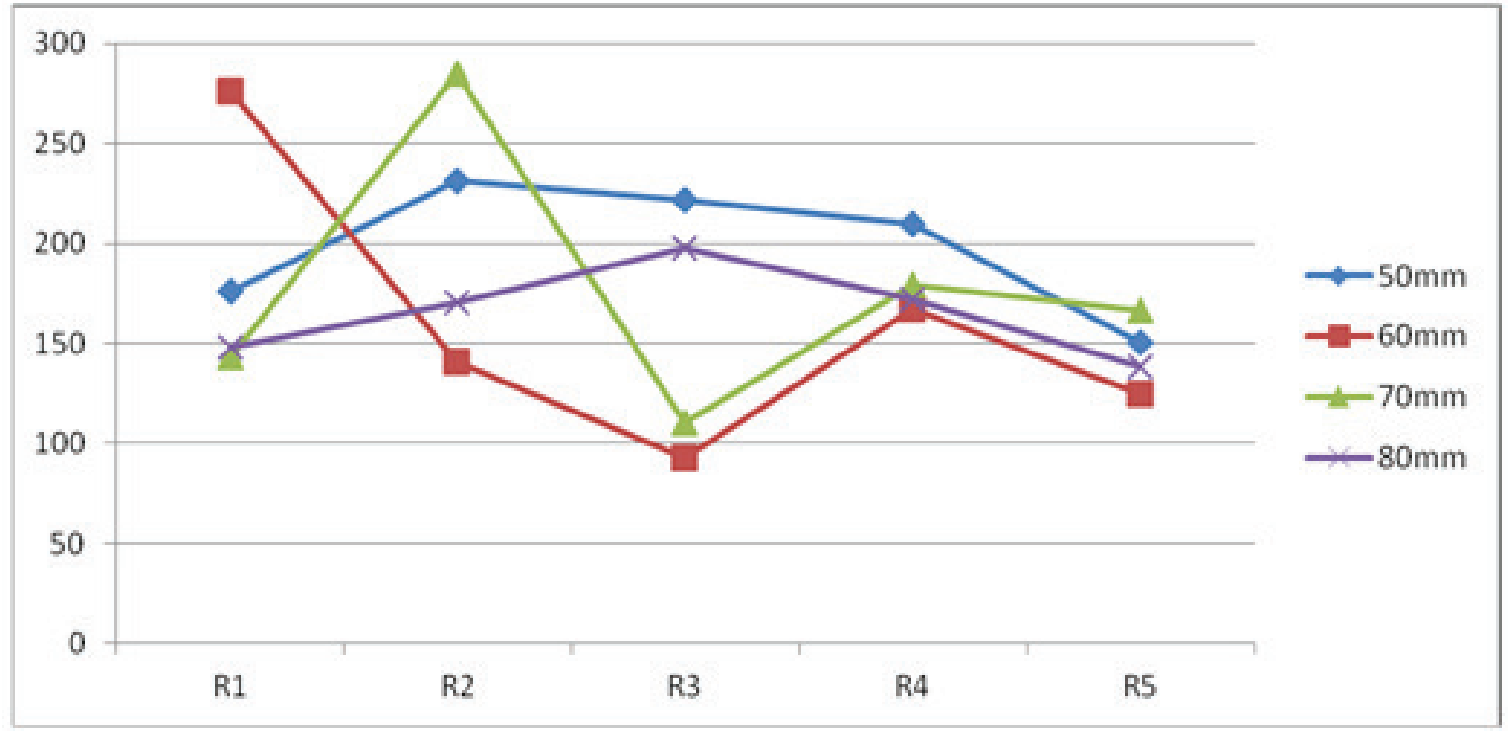

Fig. 1: Hardness for $5 \%$ soaking time at optimum $\mathrm{NaOH}$ concentration

Table 2: Hardness test for mercerization treated raffia palm fibre using $10 \% \mathrm{NaOH}$ concentration

\begin{tabular}{|c|c|c|c|c|}
\hline Fibre Replications & $\begin{array}{c}\text { Hardness HB } \\
\text { @50mm } \\
60 \mathrm{mins}(1 \mathrm{hr})\end{array}$ & $\begin{array}{c}\text { Hardness HB } \\
\text { @60mm } \\
120 \mathrm{mins}(2 \mathrm{hrs})\end{array}$ & $\begin{array}{c}\text { Hardness HB } \\
\text { @70mm } \\
180 \mathrm{mins}(3 \mathrm{hrs})\end{array}$ & $\begin{array}{c}\text { Hardness HB } \\
\text { @ 80mm } \\
240 \mathrm{mins}(4 \mathrm{hrs})\end{array}$ \\
\hline R1 & 265 & 395 & 159 & 165 \\
\hline R2 & 182 & 262 & 179 & 215 \\
\hline R3 & 187 & 305 & 145 & 197 \\
\hline R4 & 211 & 321 & 161 & 192 \\
\hline R5 & 184 & 235 & 137 & 195 \\
\hline
\end{tabular}




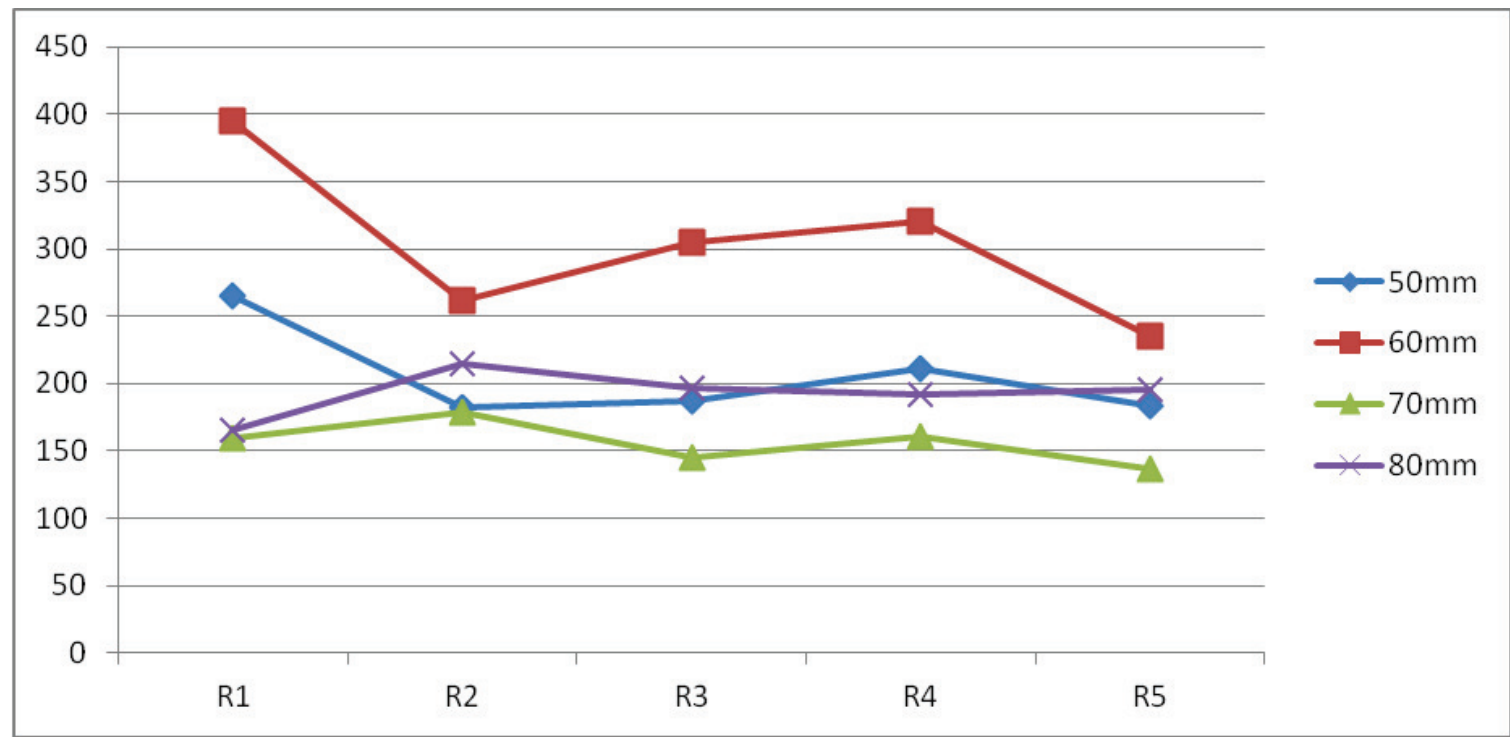

Fig. 2: Hardness for $10 \%$ soaking time at optimum $\mathrm{NaOH}$ concentration

Table 3: Tensile test for mercerization treated raffia palm fibre using 5\% $\mathrm{NaOH}$ concentration

\begin{tabular}{|c|c|c|c|c|}
\hline Fibre Replications & $\begin{array}{c}\text { Tensile Strengths } \\
\text { (Mpa)@50mm } \\
\text { 60mins(1hr) }\end{array}$ & $\begin{array}{c}\text { Tensile Strengths } \\
\text { (Mpa)@60mm } \\
\text { 120mins(2hrs) }\end{array}$ & $\begin{array}{c}\text { Tensile Strengths } \\
\text { (Mpa)@70mm } \\
\text { 180mins(3hrs) }\end{array}$ & $\begin{array}{c}\text { Tensile Strengths } \\
\text { (Mpa)@80mm } \\
\text { 240mins(4hrs) }\end{array}$ \\
\hline R1 & 754 & 444 & 768 & 409 \\
\hline R2 & 468 & 672 & 523 & 505 \\
\hline R3 & 375 & 447 & 468 & 582 \\
\hline R4 & 532 & 521 & 586 & 499 \\
\hline R5 & 610 & 450 & 600 & 505 \\
\hline
\end{tabular}

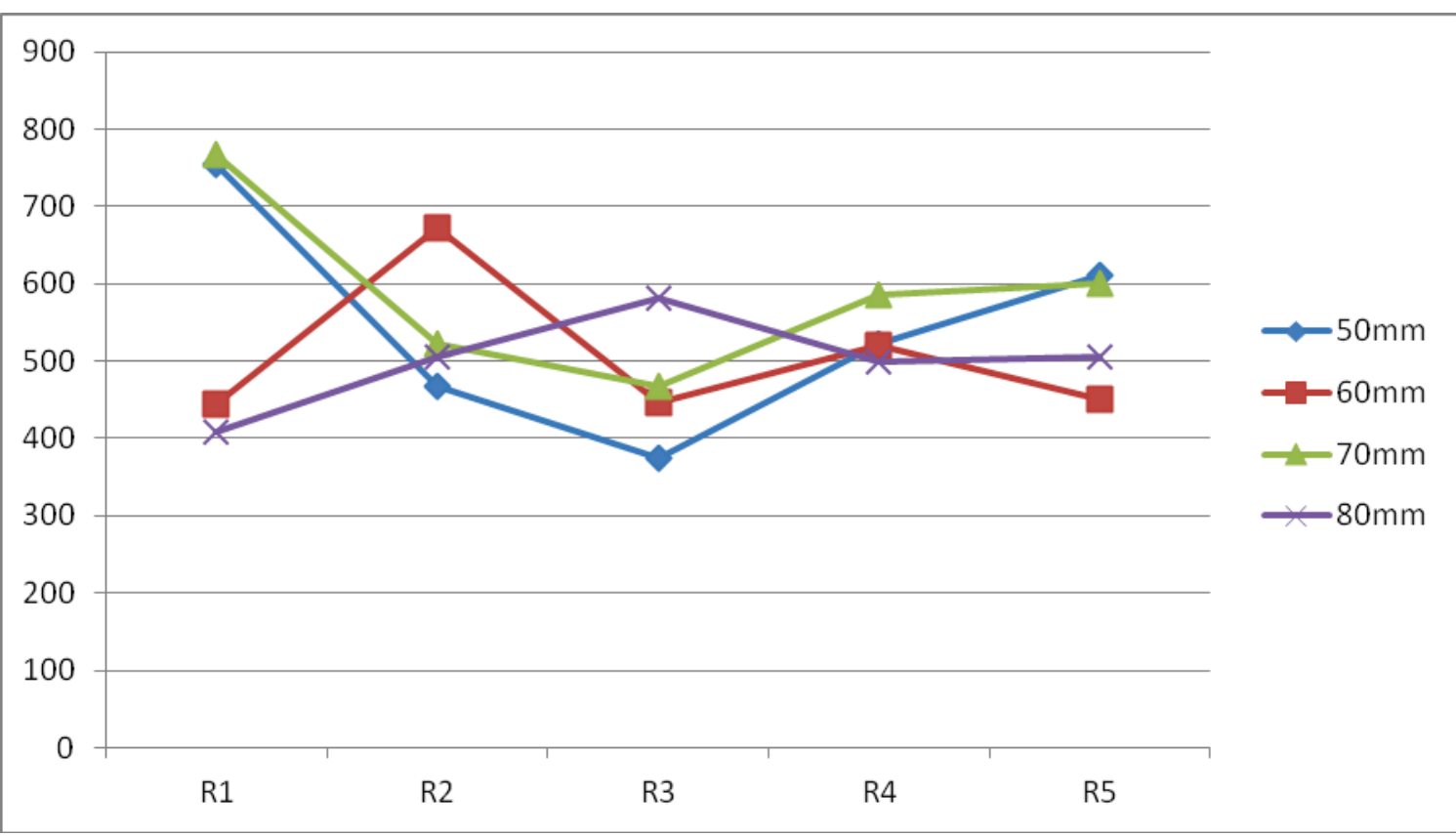

Fig. 3: Strength for 5\% soaking time at optimum $\mathrm{NaOH}$ concentration 
Table 4: Tensile test for mercerization treated raffia palm fibre using $10 \% \mathrm{NaOH}$ concentration

\begin{tabular}{|c|c|c|c|c|}
\hline Fibre Replications & $\begin{array}{c}\text { Tensile Strengths } \\
\text { (Mpa) @50mm } \\
\text { 60mins (1hr) }\end{array}$ & $\begin{array}{c}\text { Tensile Strengths } \\
\text { (Mpa)@60mm } \\
\text { 120mins (2hrs) }\end{array}$ & $\begin{array}{c}\text { Tensile Strengths } \\
\text { (Mpa)@70mm } \\
\text { 180mins(3hrs) }\end{array}$ & $\begin{array}{c}\text { Tensile Strengths } \\
\text { (Mpa)@80mm } \\
\text { 240mins(4hrs) }\end{array}$ \\
\hline R1 & 570 & 611 & 394 & 684 \\
\hline R2 & 395 & 646 & 712 & 607 \\
\hline R3 & 538 & 764 & 409 & 618 \\
\hline R4 & 501 & 674 & 505 & 636 \\
\hline R5 & 405 & 620 & 430 & 650 \\
\hline
\end{tabular}

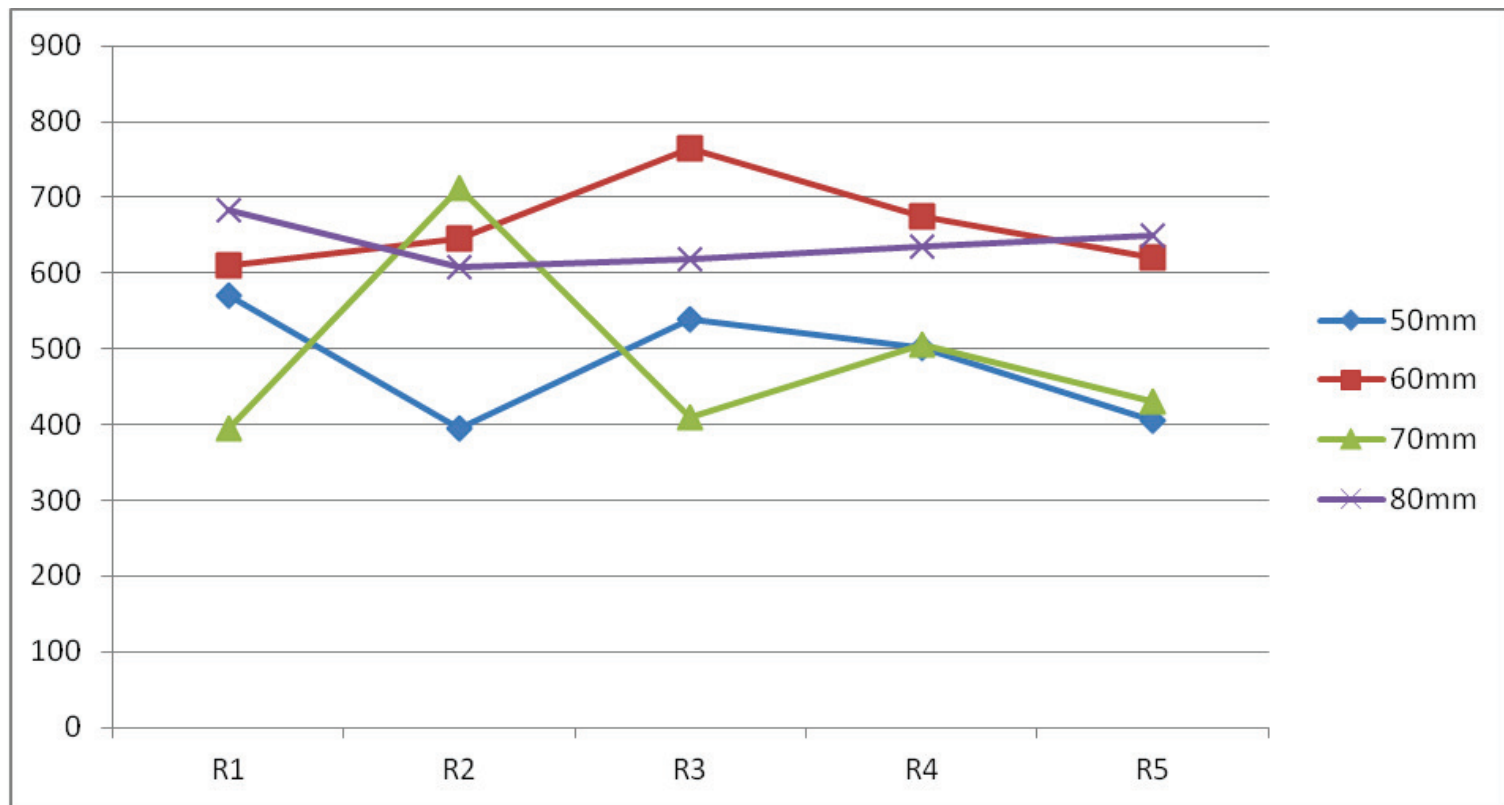

Fig. 4: Strength for $10 \%$ soaking time at optimum $\mathrm{NaOH}$ concentration

The hardness and tensile strengths of the fibre were studied at different soaking time and the results obtained from the experiments were analyzed using table 1-4 and figure 1-4. Mercerization (Alkalization) treatments of the fibre were studied using $5 \%$ and $10 \%$ concentrations of $\mathrm{NaOH}$ solution. The hardness and tensile test were examined on the mercerization treated fibres to determine the soaking time for 60,120, 180 and 240 minutes at a different length of the fibre; 50, 60, 70 and $80 \mathrm{~mm}$. Based on the experimental result of table 2, the maximum value of $395 \mathrm{HB}$ was recorded at $60 \mathrm{~mm}$ fibre length for two hours using $10 \%$ concentration of $\mathrm{NaOH}$ at different soaking time. Based on the result, it clearly shows that hardness increases with fibre treatment. Generally, mercerized treated fibre specimens possess higher hardness. These hard and brittle fibres will incessantly oppose deformation due to indentation. The result of the experiment of the tensile test of table 3 gave the highest strength of $768 \mathrm{Mpa}$ at $70 \mathrm{~mm}$ of the length of the fibre for three hours using $5 \% \mathrm{NaOH}$ concentration at a various soaking time for mercerization treated raffia palm fibre. Hence, based on the experimental results for hardness the soaking time of two hours (120mins) at fibre length of $60 \mathrm{~mm}$ using $5 \%$ $\mathrm{NaOH}$ concentration gave the highest maximum value while for strength the soaking time of three hours (180mins) at fibre length of $70 \mathrm{~mm}$ using $5 \% \mathrm{NaOH}$ concentration gave the highest tensile strength. Therefore, it is acknowledged as the standard or point of reference for fibre evolution.

\subsection{Conclusion}

All natural fibre due to excellent mechanical properties; they are available, and also agricultural products like raffia palm have an exceptional possible resource for reinforcement. The fibers are lightweight material and environmentally friendly as compared to other similar conventional composites. The major challenge of these class of fiber-reinforced composites is due to weak bonding that exists between the natural hydrophilic fibers and hydrophobic polymer matrix. This study aims to examine the soaking time on hardness, and tensile strength for mercerization (alkalization) treated or modified raffia palm fibre. For further development of the raffia palm fiber, they were gathered, extracted, processed and treated. The highly-developed raffia palm fibre can be grounded into smaller size particles and polymer reinforced to be used in the production of test samples to manufacturing various oil and gas facilities like tanks, pipes, and pipe joints among others and typical applications include aerospace, automobiles parts, household tables and chairs, window frames, laptop cases, and another consumer item. 


\section{References}

Al-Qureshi., H.A. (2001). The application of jute fibre reinforced composites for the development of a car body. UMIST Conference UK.

Bledzki, A.K. and Gassan, J. (1999). Composites reinforced with cellulose based fibres. Prog. Polym. Sci. 24:221274.

Oksman, K. (2000). Mechanical properties of natural fibre mat reinforced thermoplastic. Appl. Compos. Mater. 7: 403-414.

Rowell, R.M., Hun, J.S., and Rowell, J.S. (2000). Characterization and factors effecting fiber properties. Nat. Polym. Agrofibers Compos. Sãn Carlos-Brasil. 115-134.

Schuh, T.G. (2004). Renewable materials for automotive applications [Online]. Available: www.ienica.net/fibresseminar/schuh.pdf.

Taylor, J. (2004). Agricultural fibres for product design and development [Online].Available: http://jasont.media.mit.edu/papers.

Metcalf-Doetsch, (2013) "Tensile Test Method for the Determining of the Structural Properties of Individual Carbon Fibers," Thesis, Baylor University.

Aziz S. H, and M. P. Ansell (2004), The Effect of Alkalization and Fibre alingnment on the Mechanical and Thermal Properties of Kenaf and Hemp bast fibre Composites: Part I- Polyester resin matrix," composites: Science and technology 64(9), 1219-1230. 